\title{
The prevalence of depressive disorder among newly diagnosed patients with type 2 diabetes mellitus
}

\author{
S Amarasinghe, CJK Vidanalage, SS Williams
}

\section{Background}

Type 2 diabetes mellitus (DM) patients with co-morbid depression often experience increased morbidity and mortality. Studies in other South Asian countries have shown a high prevalence of depression in patients with newly diagnosed DM.

Aims

To study the prevalence of depression among newly diagnosed diabetes mellitus patients attending an outpatient clinic in Chilaw, Sri Lanka, and to study the association with socio demographic variables.

\section{Methods}

A cross sectional descriptive study was conducted at the medical clinic of Chilaw District General Hospital from March 2012 to November 2012, to study the prevalence of depression among a group of newly diagnosed patients with type $2 \mathrm{DM}$.

All patients diagnosed with type 2 DM within the previous two months were interviewed by a specialist in psychiatry. The presence of depression was established according to ICD 10 criteria.

\section{Results}

The study population $(n=186)$ consisted of $116(62 \%)$ females and 70 (38\%) males with a mean age of 51 years (range 27 to 80 years). Results showed that $13.4 \%(95 \% \mathrm{Cl} 8.5-18.3)$ had mild depression while $15.6 \%$ (95\% Cl $10.4-20.8$ ) had moderate depression. There were no cases of severe depression. The proportion of females with depressive disorder was significantly higher than males. There were no significant association between the prevalence of depression and other socio demographic variables such as age, marital status, education, employment, income, ethnicity or religion.

\section{Conclusion}

This study shows that a quarter of the population of newly diagnosed patients with type 2 DM have depressive disorder. This finding highlights the importance of screening patients with DM for depressive disorder.

Key words: Depression, Type 2 Diabetes mellitus, Sri Lanka.

SL J Psychiatry 2015; 6(2): 9-14

\section{Introduction}

The prevalence of clinical depression and presence of elevated depressive symptoms are higher among persons with diabetes mellitus (DM) compared with the general population (1-4). Two systematic reviews reported that prevalence of depression in patients with DM was $17.6 \%$ and $19.1 \%$ when compared to the prevalence of $10.7 \%$ in normative population $(1,2)$. A meta-analysis showed that patients with type 2 diabetes have a $24 \%$ higher risk with a relative risk of 1.24 (95\% CI 1.09-1.40) of developing depression (3).

The evidence suggests that the exposure/outcome relationship between these conditions is bidirectional and may change over the course of life. Two prospective studies in the U.S. and Japan have shown that depression doubles the risk of incident type 2 diabetes, independent of its association with other risk factors (5,6). A meta-analysis found that the relative risk for incident diabetes associated with baseline depression was 1.60 (1.37-1.88) (7).

The presence of comorbid depression in diabetes mellitus is associated with poor adherence to self-care regimens, such as glucose monitoring, diet, exercise and compliance with medication (8). In a recent WHO study, the greatest decrements in self-reported health were observed in those with both depression and diabetes, in comparison to those with depression and other chronic conditions such as angina, arthritis or asthma (9). Among patients with type 2 DM, depression was found to be strongly associated with higher health care use and expenditures, increased morbidity and mortality $(10,11)$. Given the higher healthcare expenditure and increased mortality associated with depression, it is not surprising that clinical guidelines now recommend that all patients with diabetes undergo regular screening for depression $(12,13)$.

Depression is also associated with behaviours such as smoking, physical inactivity and caloric intake that increase the risk of type 2 DM (14). It is also related to central obesity and to impaired glucose tolerance (15).

There is also evidence that depression can directly stimulate the production of proinflammatory cytokines that influence a spectrum of conditions including Diabetes Mellitus $(17,18)$. DM may increase the risk of depression because of the sense of threat and loss 
associated with receiving this diagnosis, and the substantial lifestyle changes necessary to avoid developing debilitating complications.

A studydone in Chennai of subjects with impaired glucose tolerance, found the overall prevalence of depression to be $14.3 \%$ (19). The prevalence of depression in newly diagnosed patients with diabetes was $19.7 \%$ (19). The prevalence of depression was significantly higher among subjects with diabetic retinopathy, neuropathy, nephropathy and peripheral vascular disease as compared to subjects without these complications (20). A study in Pakistan revealed that depression is significantly associated with newly diagnosed type $2 \mathrm{DM}$ among adults aged 25 to 60 years (21). The odds of mild depression among cases were 3.86 times the odds among controls (95\% CI: 2.22- 6.71), while the odds of moderate to severe depression among cases were 3.41 times the odds among controls (95\% CI: 2.07- 5.61) (21). A cross sectional study conducted among adult type 2 diabetes mellitus patients in Bangladesh showed the prevalence of depression to be $34.8 \%$, which included $20.2 \%$ with severe depression and $14.6 \%$ with mild to moderate depression (22).

Although the relationship between type 2 DM and depressive disorder is well established, only a few studies have looked at newly diagnosed type 2 DM and depressive disorder. An understanding of the temporal relationship of depression in type $2 \mathrm{DM}$ will be useful as an increased prevalence of depression from the onset may warrant early intervention. Thus the aim of this study was to describe the prevalence of depressive disorder in patients with newly diagnosed type $2 \mathrm{DM}$.

\section{Methods}

The study was conducted at the outpatient diabetic clinic of the District General Hospital, Chilaw from March 2012 to November 2012. Patients diagnosed with type 2 DM within a period of two months were recruited after informed consent. The cases of DM were operationally defined according to American Diabetic Association guidelines by a consultant physician (23).

This required the presence of any two of the following: Symptoms of polyuria (frequent urination) and polydispia (increased thirst and consequent increased fluid intake) plus random blood glucose level $>=200 \mathrm{mg} / \mathrm{dl}(11.1$ $\mathrm{mmol} / \mathrm{l})$, or fasting blood glucose level $>=126 \mathrm{mg} / \mathrm{dl}(7.0$ $\mathrm{mmol} / \mathrm{l}$ ) or 2 hour post prandial glucose level $(>=200$ $\mathrm{mg} / \mathrm{dl}(11.1 \mathrm{mmol} / \mathrm{l})$ after $75 \mathrm{~g}$ glucose load.

The first author, who is a consultant psychiatrist, assessed all newly diagnosed patients with DM, for the presence or absence of depression. The diagnosis of a depressive disorder was established by clinical interview, based on ICD 10 criteria (24). Socio demographic data on age, sex, marital status, education, employment, income, ethnicity and religion were collected by an interviewer administered questionnaire.

In the absence of relevant Sri Lankan data, a minimum sample size of 169 was calculated based on an estimated prevalence of depressive disorder of $20 \%$ as reported in previously mentioned Chennai study by Poongathai et al (19).

The ethical clearance for the study was obtained from the ethical review committee of the Colombo South Teaching Hospital, Kalubowila. Eligible participants who gave written informed consent were included in the study. All the patients who were diagnosed with depressive disorder were referred to the nearest psychiatric unit for treatment. Statistical analyses were carried out using Statistical Package for Social Sciences (SSPS) version 17.

\section{Results}

The study population ( $\mathrm{n}=186)$ consisted of $116(62 \%)$ females and 70 (38\%) males. The mean age was 51 years (range 27 years to 80 years). The study showed that $29 \%$ (CI 22.4 - 35.5) had a diagnosis of mild (13.4\%; 95\% CI 8.5 - 18.3) or moderate depression (15.6\%; $95 \%$ CI 10.4 - 20.8). There were no cases of severe depression (Table 1).

A significantly higher number of females (33.6\%) had depressive disorder compared to the males (21.4\%) $\left(\chi^{2}=13.32 ; p=0.0002\right)$. The study revealed a high rate of depression (42.1\%) among the over 65-year age group. The second highest rate was found among the 26-35 year age group. These differences were not statistically significant. There was no significant difference between marital status and the prevalence of depression (Table 2).

There was no significant association between education levels ( $p=0.98)$ or income status and depression $(p=0.21)$.

\begin{tabular}{|c|c|c|c|}
\hline Classification of depression & No. & $\%$ & 95\% Confidence Interval \\
\hline No depression & 132 & 71.0 & \\
\hline Mild & 25 & 13.4 & $8.5-18.3$ \\
\hline Moderate & 29 & 15.6 & $10.4-20.8$ \\
\hline Total & 186 & 100.0 & \\
\hline
\end{tabular}




\begin{tabular}{|c|c|c|c|c|c|c|c|}
\hline \multirow{2}{*}{ Characteristics } & \multicolumn{2}{|c|}{$\begin{array}{l}\text { Depression } \\
n=54\end{array}$} & \multicolumn{2}{|c|}{$\begin{array}{l}\text { No depression } \\
n=132\end{array}$} & \multicolumn{2}{|c|}{$\begin{array}{l}\text { Total } \\
\mathrm{n}=186\end{array}$} & \multirow[t]{2}{*}{ Test and $p$} \\
\hline & No. & $\%$ & No. & $\%$ & No. & $\%$ & \\
\hline \multicolumn{8}{|c|}{ Age group in years } \\
\hline $26-35$ & 5 & 35.7 & 9 & 64.3 & 14 & 100.0 & $\begin{array}{l}\chi^{2}=2.77 \\
d f=4\end{array}$ \\
\hline $36-45$ & 9 & 22.5 & 31 & 77.5 & 40 & 100.0 & $p=0.60$ \\
\hline $46-55$ & 20 & 29.0 & 49 & 71.0 & 69 & 100.0 & \\
\hline $56-65$ & 12 & 27.3 & 32 & 72.7 & 44 & 100.0 & \\
\hline$>65$ & 8 & 42.1 & 11 & 57.9 & 19 & 100.0 & \\
\hline \multicolumn{8}{|l|}{ Sex } \\
\hline Male & 15 & 21.4 & 55 & 78.6 & 70 & 100.0 & $\begin{array}{l}\chi^{2}=13.33 \\
d f=1\end{array}$ \\
\hline Female & 39 & 33.6 & 77 & 66.4 & 116 & 100.0 & $p=0.0002$ \\
\hline \multicolumn{8}{|l|}{ Marital status } \\
\hline Married & 35 & 25.7 & 101 & 74.3 & 136 & 100.0 & $\begin{array}{l}\chi^{2}=2.67 \\
d f=1\end{array}$ \\
\hline Single ${ }^{1}$ & 1 & 25.0 & 3 & 75.0 & 4 & 100.0 & $p=0.10$ \\
\hline \multicolumn{8}{|l|}{ Not living } \\
\hline together ${ }^{1}$ & 18 & 39.1 & 28 & 60.9 & 46 & 100.0 & \\
\hline
\end{tabular}

$P$ values are based on $\chi^{2}$ tests for categorical variables and t-test for continuous variables. Rows (1) amalgamated for statistical purposes,

Not living together (Divorced/ Separated/ Spouse Living Aboard/ Spouse dead)

Similarly the study did not show any significant association between ethnicity and religion with depression. In addition there was no association between current employment status and depression (Table 3).

\section{Discussion}

According to our findings, more than one fourth of the patients with newly diagnosed Type 2 DM had comorbid mild or moderate depressive disorder. An epidemiological study done by Ball et al. reported that the life-time prevalence of depression in a Sri Lankan population was $6.6 \%$ (25). A study conducted in the Northern province during the post conflict period (2013) revealed that the prevalence of major depression was 4.5\% (95\% CI: 4.14.9) and mild depression was $13.3 \%$ (95\% CI: $12.7-13.9)$ (26). Therefore the prevalence of depression in our sample of newly diagnosed DM patients is much higher than the lifetime prevalence of depressive disorder reported for Sri Lanka and the prevalence of major depression in northern Sri Lanka during the post conflict period.

There are other studies done on similar populations with chronic physical illnesses in Sri Lanka. Sumanatissa et al reported that the prevalence of depression was $27.9 \%$ among 140 patients with chronic renal failure in the North Central province of Sri Lanka (27). Monaragala reported a prevalence of depression of $38.4 \%$ among 211 patients who presented to a tertiary cardiology center in the
Central province following an acute myocardial infarction (28). Weerawardena studied 143 HIV patients and reported a $27.3 \%$ prevalence of depression (29). All these studies show a higher prevalence of depressive disorder among these diseased groups.

Asghar et al assessed depressive symptoms in 184 newly diagnosed diabetic subjects in Bangladesh using the Montogomery and Asberg Depression Rating Scale (MADRS) (30). They found that $29 \%$ of male and $30.5 \%$ of female participants with diabetes had depression, which is very similar to the findings of our study (30).

This study did not show any significant association between age and depression. However $42 \%$ of the elderly (over 65) group had depression. Raval et al reported that advancing age is associated with depression in patients with Type 2 DM in India and Khuwaja et al. too reported a higher incidence of depression among the elderly in a Pakistani population (31, 32). It is reported that older patients face many challenges including social isolation, multiple diseases and disabilities; hence they may be more prone to developing psychological conditions.

This study showed a higher prevalence of depression among females than males and similarly, many studies done among newly diagnosed diabetes and long standing DM have reported higher incidence of depression among females $(33,34)$. It is perhaps in keeping with population trends in general, that more females than males are diagnosed with depressive disorder (35). 


\begin{tabular}{|c|c|c|c|c|c|c|c|}
\hline \multirow{2}{*}{ Characteristics } & \multicolumn{2}{|c|}{$\begin{array}{l}\text { Depression } \\
n=54\end{array}$} & \multicolumn{2}{|c|}{$\begin{array}{l}\text { No depression } \\
n=132\end{array}$} & \multicolumn{2}{|c|}{$\begin{array}{l}\text { Total } \\
n=186\end{array}$} & \multirow[t]{2}{*}{ Test and $p$} \\
\hline & No. & $\%$ & No. & $\%$ & No. & $\%$ & \\
\hline \multicolumn{8}{|l|}{ Level of education } \\
\hline No education ${ }^{1}$ & 1 & 25.0 & 3 & 75.0 & 4 & 100.0 & $\begin{array}{l}\chi^{2}=0.17 \\
d f=3\end{array}$ \\
\hline Grade $1-5^{1}$ & 11 & 28.2 & 28 & 71.8 & 39 & 100.0 & $p=0.98$ \\
\hline Grade 6 - 10 & 21 & 30.4 & 48 & 69.6 & 69 & 100.0 & \\
\hline $\mathrm{GCE}(\mathrm{O} / \mathrm{L})$ passed & 12 & 27.3 & 32 & 72.7 & 44 & 100.0 & \\
\hline GCE $(A / L)$ passed $^{2}$ & 5 & 27.8 & 13 & 72.2 & 18 & 100.0 & \\
\hline \multicolumn{8}{|l|}{ Higher/technical } \\
\hline Education ${ }^{2}$ & 4 & 33.3 & 8 & 66.7 & 12 & 100.0 & \\
\hline \multicolumn{8}{|l|}{ Ethnicity } \\
\hline Sinhala & 47 & 29.9 & 110 & 70.1 & 157 & 100.0 & $\begin{array}{l}\chi^{2}=0.39 \\
d f=1\end{array}$ \\
\hline SL Tamil ${ }^{1}$ & 3 & 20.0 & 12 & 80.0 & 15 & 100.0 & $p=0.53$ \\
\hline Muslim ${ }^{1}$ & 4 & 28.6 & 10 & 71.4 & 14 & 100.0 & \\
\hline \multicolumn{8}{|l|}{ Religion } \\
\hline Buddhist & 24 & 32.4 & 50 & 67.6 & 74 & 100.0 & $\begin{array}{l}\chi^{2}=0.69 \\
d f=2\end{array}$ \\
\hline Christian & 25 & 27.5 & 66 & 72.5 & 91 & 100.0 & $p=0.41$ \\
\hline Islam ${ }^{1}$ & 4 & 26.7 & 11 & 73.3 & 15 & 100.0 & \\
\hline $\mathrm{Hindu}^{1}$ & 1 & 16.7 & 5 & 83.3 & 6 & 100.0 & \\
\hline \multicolumn{8}{|c|}{ Average Monthly Income (rs.) } \\
\hline Less than 10,000 & 17 & 33.3 & 34 & 66.7 & 51 & 100.0 & $\begin{array}{l}\chi^{2}=3.15 \\
d f=2\end{array}$ \\
\hline $10,000-20,000$ & 22 & 33.8 & 43 & 66.2 & 65 & 100.0 & $p=0.21$ \\
\hline $20,001-30,000^{1}$ & 10 & 19.2 & 42 & 80.8 & 52 & 100.0 & \\
\hline $30,001-40,000^{1}$ & 4 & 28.6 & 10 & 71.4 & 14 & 100.0 & \\
\hline More than $40,000^{1}$ & 1 & 25.0 & 3 & 75.0 & 4 & 100.0 & \\
\hline
\end{tabular}

Rows (1), (2) amalgamated for statistical purposes

This study did not show any difference in depression according to marital status. However previous studies among those with long standing DM have reported a significantly higher prevalence of depression among unmarried participants with diabetes $(36,37)$.

Several studies have reported associations between lower educational level or lower socio-economic status and depression in DM (38-40). However our study did not find an association between depression and income or educational level.

\section{Limitations}

This study had a relatively small sample size and this may have influenced the detection of associations between depression and different demographic variables. The lack of a control comparison group is also a limitation, and prevents further exploration of the possible effects of diabetes on depression.

\section{Conclusions}

The findings of this study highlight the importance of screening for depressive disorder in patients with type 2 $\mathrm{DM}$. All doctors working in the general medical setting should therefore be educated about the association of depressive disorder with DM and should be given adequate training to identify and treat depression in DM.

\section{Declaration of interest}

None declared

S Amarasinghe, CJ Kande Vidanalage, General Hospital, Chilaw

SS Williams, Faculty of Medicine, University of Kelaniya, Ragama

Corresponding author: S Amarasinghe

Email: Sajeewana.amarasinghe@gmail.com

DOI http://dx.doi.org/10.4038/sljpsyc.v6i2.8074 


\section{References}

1. Ali S, Stone MA, Peters JL, Davies MJ, Khunti K. The Prevalence of co-morbid depression in adults with type 2 diabetes: a systematic review and meta-analysis. Diabetic Med 2006; 23:1165-73.

2. Roy T, Lloyd CE. Epidemiology of depression and diabetes: a systematic review. J Affect Disord 2012; 142 Suppl: S8-21.

3. Nouwen A, Winkley K, Twisk J, et al. Type 2 diabetes mellitus as a risk factor for the onset of depression: a systematic review and meta-analysis.European Depression in Diabetes (EDID) Research Consortium. Diabetologia 2010; 53(12): 2480-6.

4. Fisher L, Skaff MM, Mullan JT, Arean P, Glasgow R, Masharani U. A longitudinal study of affective and anxiety disorders, depressive affect and diabetes distress in adults with type 2 diabetes. Diabet Med 2008; 25(9): 1096-101.

5. Eaton WW, Armenian HA, Gallo J, Pratt L, Ford DE. Depression and risk for onset of type II diabetes: a prospective population-based study. Diabetes Care 1996; 19: 1097-102.

6. Kawakami N, Takatsuka N, Shimizu H, Ishibashi H. Depressive symptoms and occurrence of type 2 diabetes among Japanese men. Diabetes Care 1999; 22(7): 1071-6.

7. Mezuk B, Eaton WW, Albrecht S, Golden SH. Depression and type 2 diabetes over the lifespan: a meta-analysis. Diabetes Care 2008; 31(12): 2383-90.

8. Weber B, Schweiger U, Deuschle M, Heuser I. Major depression and impaired glucose tolerance. Exp Clin Endocrinol Diabetes 2000; 108: 187-190.

9. Egede LE. Diabetes, major depression, and functional disability among US adults. Diabetes Care 2004; 27: 421-8.

10. Moussavi S, Chatterji S, Verdes E, Tandon A, Patel V, Ustun B. Depression, chronic diseases, and decrements in health: results from the World Health Surveys. Lancet 2007; (9590): 851-8.

11. Katon W, Fan M-Y, Unützer J, Taylor J, Pincus H, Schoenbaum M. Depression and diabetes: a potentially lethal combination. J Gen Intern Med 2008; 23: 1571-5.

12. Dunning T, Sinclair A, Colagiuri S. New IDF Guideline for managing type 2 diabetes in older people. Diabetes Res Clin Pract 2014; 103(3): 538-40.

13. American Diabetes Association. Standards of medical care in diabetes-2012. Diabetes Care 2012; 35 Suppl 1: S11-63.

14. Willi C, Bodenmann P, Ghali W, Faris D,Cornuz J. Active smoking and the risk of type 2 diabetes: a systematic review and meta-analysis. JAMA 2007; 298(22): 2654-64.

15. Strine T, Mokdad A, Dube S, et al. The association of depression and anxiety with obesity and unhealthy behaviours among community-dwelling US adults. Gen Hosp Psychiatry 2008; 30(2): 127-37.

16. Golden SH. A review of the evidence for a neuroendocrine link between stress, depression and diabetes mellitus. Curr Diabetes Rev 2007: 3(4): 252-9.

17. Kiecolt-Glaser JK, Glaser R. Depression and immune function: central pathways to morbidity and mortality. J Psychosom Res 2002; 53(4): 873-6.
18. Doyle T, Halaris A, Rao M. Shared neurobiological pathways between type 2 diabetes mellitus and depressive symptoms. A review of morphological and neurocognitive findings. Curr Diab Rep 2014; 14(12): 560.

19. Poongothai S, Anjana RM, Pradeepa R, Ganesan A, Umapathy N, Mohan V. Prevalence of depression in relation to glucose intolerance in urban south Indians--the Chennai Urban Rural Epidemiology Study (CURES-76). Diabetes Technol Ther 2010; 12(12): 989-94.

20. Poongothai S, Anjana RM, Pradeepa R, et al. Association of depression with complications of type 2 diabetes-the Chennai Urban Rural Epidemiology Study (CURES102).J Assoc Physicians India 2011; 59: 644-8.

21. Perveen S, Otho MS, Siddiqi MN, Hatcher J, Rafique G. Association of depression with newly diagnosed type 2 diabetes among adults aged between 25 to 60 years in Karachi, Pakistan. Diabetol Metab Syndr 2010; 2:17.

22. Rahman M, Rahman MA, Flora MS, Rakibuz-Zaman M. Depression and associated factors in diabetic patients attending an urban hospital of Bangladesh. Int J Collaborat Res Intern Med Public Health 2011; 3: 65-76.

23. American Diabetes Association: Standards of Medical Care in Diabetes-2007. Diabetes Care 2007; 30: S4-S41.

24. World Health Organisation (WHO). The ICD 10 classification of mental and behavioural disorders: criteria for Research. Geneva: WHO; 1992.

25. Ball HA, Siribaddana SH, Kovas Y. Epidemiology and symptomatology of depression in Sri Lanka: a cross sectional population based survey in Colombo District. J Affect disord 2010; 123(1-3): 188-196.

26. Senarath U, Wickramage K, Peiris SL. Prevalence of depression and its associated factors among patients attending primary care settings in the post-conflict Northern Province in Sri Lanka: a cross-sectional study. BMC Psychiatry 2014; 14: 85.

27. Sumanathissa M, De Silva VA, Hanwella R. Prevalence of major depressive episodes among patients with pre dialysis chronic kidney disease. Int J Psychiatry Med 2011; 41(1): 47-56.

28. Monaragala RMM. Prevalence of depression in recent myocardial infarction. A hospital based study (unpublished dissertation). Colombo: Postgraduate Institute of Medicine, University of Colombo 2008.

29. Weerawardena SN. Depression among HIV sero positive individuals presenting at the National STD and AIDS control programme, Colombo (unpublished dissertation). Colombo: Postgraduate Institute of Medicine, University of Colombo 2011.

30. Asghar S, Hussain A, Ali SMK, Khan AKA, Magnusson A. Prevalence of depression and diabetes: a populationbased study from rural Bangladesh. Diabetic Med 2007; 24(8): 872-7.

31. Raval A, Dhanaraj E, Bhansali A, Grover S, Tiwari P. Prevalence and determinants of depression in type 2 diabetes patients in a tertiary care centre. Indian J Med Res 2010; 132: 195-200.

32. Khuwaja AK, Lalani S, Dhanani R, Azam IS, Rafique G, White F. Anxiety and depression among outpatients with type 2 diabetes: A multi-centre study of prevalence and associated factors. Diabetol Metab Syndr 2010; 2: 72.

33. Aujla N, Abrams KR, Davies MJ, Taub N, Skinner TC, Khunti K. The prevalence of depression in white-European 
and South-Asian people with impaired glucose regulation and screen-detected type 2 diabetes mellitus. PLoS One 2009 Nov 9; 4(11): e7755.

34. Rahman M, Rahman MA, Flora MS, Karim R, Zaman MR. Depression and its association with sociodemographic characteristics among type 2 diabetes mellitus patients of Bangladesh. Mymensingh Med J 2012; 21(3): 490-6.

35. Kessler RC, McGonagle KA, Swartz M, Blazer DG, Nelson CB. Sex and depression in the national co morbidity survey I : lifetime prevalence, chronicity and recurrence. J Affect Disord 1993; 29(2-3): 85-96.

36. Agbir TM, Audu MD, Adebowale TO, Goar SG. Depression among medical outpatients with diabetes: A cross-sectional study at Jos University Teaching Hospital, Jos, Nigeria. Ann Afr Med 2010; 9(1): 5-10.
37. Engum A. The role of depression and anxiety in onset of diabetes in a large population-based study. J Psychosom Res 2007; 62 (1): 31-38.

38. Camethon MR, Kinder LS, Fair JM, et al. Symptoms of depression as a risk factor for incident diabetes: findings from the National Health and Nutrition Examination Epidemiologic Follow-up Study, 1971-1992. Am J Epidemiol 2003; 158(5): 416-23

39. Peyrot MF, Rubin RR. Levels and risks of depression and anxiety symptomatology among diabetic adults. Diabetes Care 1997; 20(4): 585-90.

40. Joseph N, Unnikrishnan B, Raghavendra Babu YP, Kotian MS, Nelliyanil M. Proportion of depression and its determinants among type 2 diabetes mellitus patients in various tertiary care hospitals in Mangalore city of South India. Indian J Endocrinol Metab 2013; 17(4): 681-8. 